\title{
Ureteral erosion of a transvaginal tape
}

\author{
Homan Miraliakbari, BSc(Hons), MSc, MD, ${ }^{*}$ Edward Tse, MDCM, FRCSC ${ }^{\dagger}$
}

"University of Alberta, Division of Urology, University of Saskatchewan, Regina Core Surgery Program; ${ }^{\dagger}$ Clinical Professor, Department of Surgery, University of Saskatchewan, Saskatoon, SK

Cite as: Can Urol Assoc J 2011;5 (3):e44-e46; D01:10.5489/cuaj.10125

\section{Abstract}

The transvaginal tape (TVT) has gained acceptance as an effective surgical treatment of female stress incontinence. The popularity of this procedure is due to its relatively high success rate, short operative time and low incidence of complications. However, this procedure is not without potential for complications; the erosion of synthetic tape materials into adjacent pelvic structures has been reported. This report represents the first published case of ureteral erosion of TVT.

\section{Introduction}

Since it was first described in $1996,{ }^{1}$ the transvaginal tape (TVT) procedure for the treatment of female stress incontinence has largely replaced the previously described antiincontinence surgeries. ${ }^{2}$ It has been described by some as the gold standard treatment for female stress urinary incontinence. ${ }^{2}$ The TVT procedure and related transobturator tape (TOT) procedure are minimally invasive surgical treatments that have been shown to be efficacious and safe in several randomized controlled trials. ${ }^{3}$ Although infrequent, intraoperative injuries to other pelvic structures related to the TVT procedure have been reported. These include injuries to the bladder, urethra, bowel, vaginal wall, nearby nerves, as well as potential risks of bleeding and hematoma development. ${ }^{4}$ Postoperative complications have also been reported and include pain, urinary retention, urge symptoms, infection, vesico-vaginal fistula development and erosion of tape material into adjacent pelvic organs. ${ }^{5} \mathrm{~A}$ literature search revealed one case report of ureteral orifice erosion of a TVT, ${ }^{6}$ which was recognized several months following an intra-operative bladder rupture during a TVT procedure. In the report, the authors outline the course of a patient who had persistent bladder erosion of her TVT material that eventually eroded through her ipsilateral ureteral orifice about 11 months after TVT placement.

\section{Case report}

A 78-year-old female presented to the emergency department with a 4-day history of dysuria and a 2-day history of progressive left flank pain. She described the pain as sharp and intermittent; it progressed to 7 of 10 in intensity over the 4-day history. It originated in her left costovertebral angle and radiated anteriorly and inferiorily toward her genitals. She had no associated nausea or vomiting, fever, chills or gross hematuria. Her medical history included Parkinson's disease, hypertension, and frequent urinary tract infections. Her past surgeries included an open cholecystectomy, hysterectomy with anterior culposuspension and a TVT procedure performed 4 years before her current presentation for treatment of stress urinary incontinence. The TVT procedure, hysterectomy and anterior culposuspension were performed together during a single operation. Other pertinent historical points included 3 vaginal births and ciprofloxacin use, prescribed by her general practitioner for symptoms of dysuria which began 1 day before the onset of her pain symptoms. Her medications included amlodipine, lisinopril, venlafaxine, bromazepam, carbidopa, levodopa and rabeprazole. She had no history of immunomodulator, immunosuppressor or regular anti-inflammatory medication use.

Her physical examination revealed a mildly overweight patient in no distress. Abdominal exam revealed scars from previous surgeries, but no tenderness or organomegaly. The patient did have tenderness to percussion at her left costovertebral angle and flank.

Laboratory investigations revealed a mild elevation in her white blood cell count $\left(11.3 \times 10^{9} / \mathrm{L}\right)$, but normal hemoglobin, hematocrit, renal panel, electrolyte panel, liver function tests, amylase and bilirubin levels. Her urinalysis showed trace hematuria and was negative for nitrates, leukocyte esterase and bacteria.

Based on the findings of the history and physical, as well as the laboratory tests, we suspected a ureteral stone was responsible for this patient's symptoms and a computed tom- 


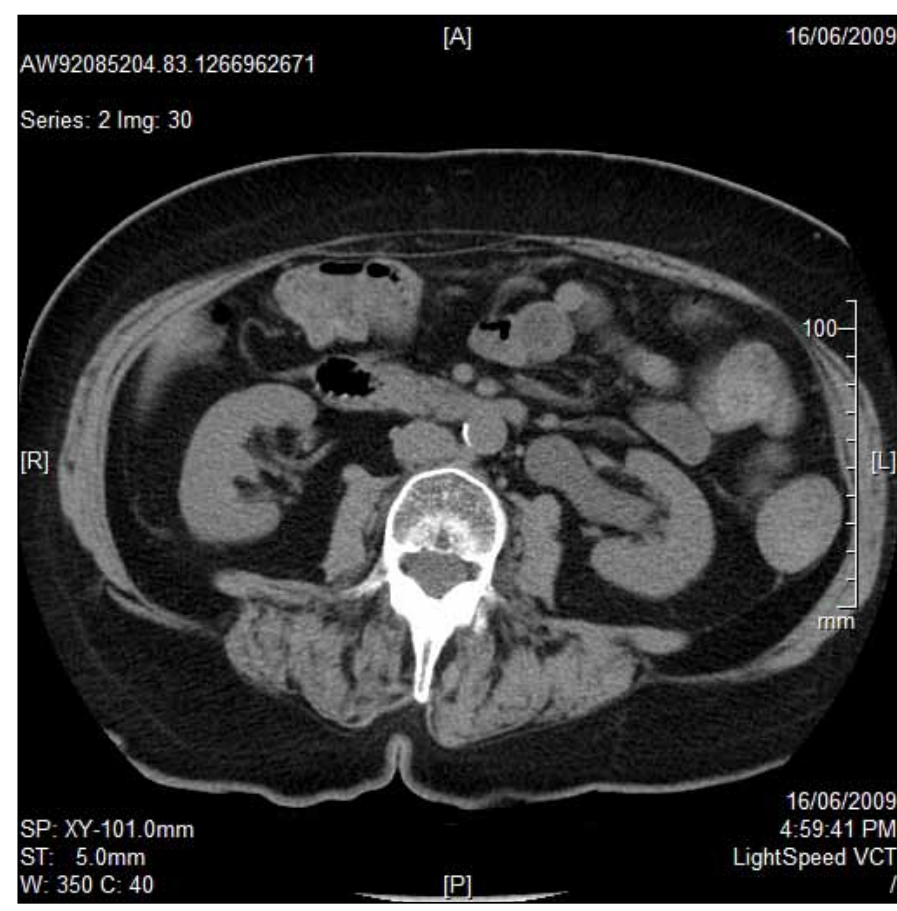

Fig. 1. Computed tomogram showing hydronephrosis and hydroureter.

ography of the kidneys, ureters and bladder was ordered. This scan revealed marked hydronephrosis and hydroureter (Fig. 1), as well as a 1.3-cm calculus in the distal ureter (Fig. 2). After explanation of these findings to the patient, consent was obtained for ureteroscopic laser lithotripsy to treat her left ureteral stone.

After perfoming an intra-operative retrograde urethrogram of the left ureter to confirm the location of the stone, a guide wire was passed beyond the stone up to the renal pelvis, followed by a flexible ureteroscope up to the level of the stone. After being lasered into fragments, the stone had formed around a foreign body that had eroded into the distal left ureter (Fig. 3). The foreign body resembled the tape material used to treat this patient's stress incontinence 4 years earlier. A 24-6 double-J stent was inserted into the patient's left urinary collecting system. The operative findings and treatment options were discussed with the patient and she elected to undergo a laparoscopic distal ureterectomy to remove the affected portion of her left distal ureter with immediate ureteroneocystostomy of the proximal portion. The tape material was excised on the left side.

It was noted intraoperatively that the course of the TVT was not identical on the patient's left and right side. The TVT was closer in approximation to the bladder base on the patient's left side, which may represent inappropriate course of placement of the TVT needle or inadequate deflection of the lower urinary tract during needle placement. It is also possible that the concomitant anterior culposuspension and hysterectomy caused anatomic distortion of the lower urin-

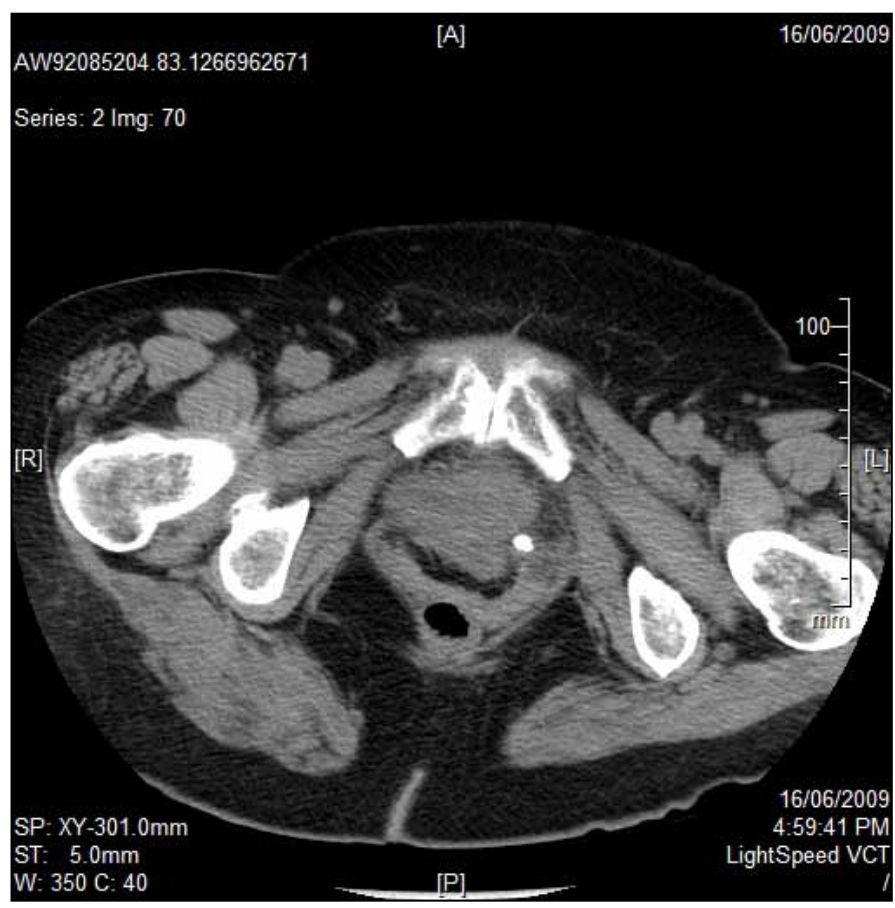

Fig. 2. Computed tomogram showing distal left ureteric calculus.

ary tract and pelvic contents, which led to the erosion of the tape material into the distal ureter rather than the more common locations of TVT material erosion.

\section{Conclusion}

Erosion of tape material into nearby pelvic organs is an uncommon complication of the TVT procedure. Previous cases of vaginal, ${ }^{7}$ bladder $^{3,6}$ and urethral $^{8}$ erosion caused by tape material have been reported. This case report illustrates another rare postoperative complication of the TVT procedure which should be considered in a patient presenting with postoperative pain out of keeping with the TVT procedure, as well as recurrent urinary tract infections following this procedure.

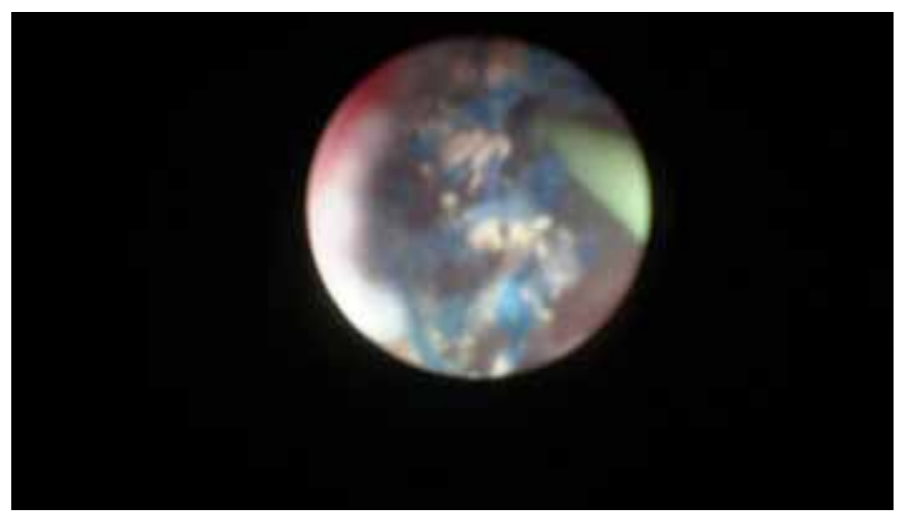

Fig. 3. Ureteroscopic image showing tape material that has eroded through the posterior wall of the left ureter. 
Miraliakbari et al.

Competing interests: None declared.

This paper has been peer-reviewed.

\section{References}

1. Ulmsten U, Henricksson L, Johnson P, et al. An ambulatory surgical procedure under local anaesthesia for treatment of female urinary incontinence. Int Urogynecol J Pelvic Floor Dysfunct 1996;7:81-5.

2. Latthe PM, Foon R, Tooza-Hobson P. Transobturator and retropubic tape procedures in stress urinary incontinence: a systematic review and meta-analysis of effectiveness and complications. BJOG 2007;1 14:522-31.

3. Abdel-Fattah M, Ramsay I, Pringle S. Lower urinary tract injuries after transobturator tape insertion by different routes: a large retrospective study. BJOG 2006;13:1377-81.
4. Tamussino K, Hanzal E, Kolle D. Transobturator tapes for stress urinary incontinence: results of the Austrian registry. Am J Obstet Gynecol 2007; 197:634-5.

5. Boustead $G B$. The tension free vaginal tape for treating female stress urinary incontinence. BJU Int 2002;89:687-93.

6. Derpapas A, Digesu GA, Panayi D, et al. A persistent bladder erosion with ureteric involvement following mesh augmented repair of cystocele. Am J Obstet Gynecol 2010;202:e5-e7.

7. Koch YK, Zimmern P. A critical overview of the evidence base for the contemporary surgical management of stress incontinence. Curr Opin Urol 2008;18:370-6.

8. Majar S, Tchetgen M, Van Atwerp A, et al. Urethral erosion of tension free vaginal tape. Urology 2002;59:601.

Correspondence: Dr. Homan Miraliakbari, University of Alberta, Division of Urology, University of Saskatchewan, Regina Core Surgery Program, Urology Associates, 537 Medical Arts Building, 750 Spadina Crescent East, Saskatoon, SK S7K 3H3; fax: 306-653-4386; homanmir62@hotmail.com 